\title{
Financiamento da Educação Básica: \\ o grande desafio para os municípios ${ }^{1}$
}

\author{
Financing of Basic Education: \\ the big challenge for the municipalities
}

\section{Financiación de la Educación Básica:}

el gran reto para los municípios

THIAGO ALVES*

Universidade Federal de Goiás, Goiânia- GO, Brasil.

\begin{abstract}
ADRIANA A. DRAGONE SILVEIRA**
\end{abstract}
Universidade Federal do Paraná, Curitiba- PR, Brasil.

GABRIELA SCHNEIDER ${ }^{* * *}$

Universidade Federal do Paraná, Curitiba- PR, Brasil.

\begin{abstract}
RESUMO: Este artigo tem como objetivo avaliar o desafio da adoção de parâmetros de qualidade nacionais utilizados para calcular o $\mathrm{CAQ/}$ CAQi no orçamento municipal. Para tanto, analisa, por meio da ferramenta Simulador de Custo Aluno-Qualidade (SimCAQ), a distância entre o investimento atualmente realizado e o que seria necessário para conseguir financiar o CAQi em três municípios de mesmo porte populacional, mas com características distintas quanto à realidade orçamentária-financeira. Os resultados indicam o impacto de um padrão de qualidade nacional para a garantia da oferta de ensino em
\end{abstract}

\footnotetext{
* Doutor em Administração pela Faculdade de Economia, Administração e Contabilidade da Universidade de São Paulo. Atualmente é professor na Universidade Federal de Goiás. Atua no Programa de Pós-Graduação em Educação da UFPR e no Programa de Pós-Graduação em Administração da UFG. E-mail: <thiagoalves.edu@gmail.com>.

** Mestre e doutora em Educação pela Universidade de São Paulo. Atualmente é professora associada da Universidade Federal do Paraná. Atua nos cursos de graduação e pós-graduação na linha de Políticas Educacionais. E-mail: <adrianadragone@yahoo.com.br>.

*** Mestre e doutora em Educação pela Universidade Federal do Paraná. É professora no Departamento de Planejamento e Administração Escolar da UFPR. Atualmente coordena o Curso de Aperfeiçoamento em Educação, Pobreza e Desigualdade Social no âmbito da UFPR. E-mail: <gabis0905@gmail.com.
} 
condições de qualidade e mostram a necessidade de ampliar as fontes de recursos de modo a garantir o financiamento do CAQi.

Palavras-chave: Custo Aluno-Qualidade. Financiamento da educação básica. Políticas educacionais. Planejamento educacional.

ABSTRACT: This article aims to evaluate the challenge of adopting the national quality criteria used to calculate Cost of Quality Education per Student (CAQ)/ Cost of Initial Quality Education per Student (CAQi) in the municipal budget. For this purpose, it analyses through the Cost of Quality Education per Student Simulator (SimCAQ) tool, the distance between the investments currently made and what is needed to obtain CAQi in three municipalities of the same demographic size, but diferente budget-financial characteristics. The results show the impact of a national quality standard to guarantee quality education provision and show the need to expand as sources of funds to guarantee or finance CAQi.

Keywords: Cost of Quality Education per Student. Financing of basic education. Educational policies. Educational planning.

RESUMEN: Este artículo tiene como objetivo evaluar el desafío de la adopción de parámetros de calidad nacionales utilizados para calcular el Costo Alumno-Calidad (CAQ)/ Costo Alumno-Calidad Inicial (CAQi) en el presupuesto municipal. Con este fin analiza, utilizando la herramienta Simulador de Costos Alumno-Calidad (SimCAQ), la distancia entre la inversión que se realiza actualmente y lo que sería necesario para poder financiar el CAQi en tres municipios de igual porte poblacional, pero con características distintas em cuanto a la realidad presupuestario-financiera. Los resultados indican el impacto de um estándar de calidad nacional para garantizar la provisión de educación de calidad y muestran la necesidad de ampliar las fuentes de financiación para garantizar la financiación del CAQi.

Palabras clave: Costo Alumno-Calidad. Financiación de la educación básica. Políticas educacionales. Planificación educativa. 


\section{Introdução}

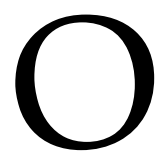

debate sobre Custo Aluno-Qualidade e Custo Aluno-Qualidade Inicial (CAQ/

CAQi), de algum modo, tem focalizado os valores monetários por aluno, em geral, considerados baixos, suficientes ou altos, a depender da visão do analista em relação à importância dos insumos materiais na garantia do direito à educação de qualidade.

Neste artigo, o propósito é avaliar o desafio da adoção de parâmetros de qualidade nacionais utilizados para calcular o CAQ no orçamento de municípios com características socioeconômicas e educacionais diversas. Objetivamente, será analisada a distância entre o investimento atualmente realizado e o que seria necessário para conseguir financiar o CAQi em diferentes municípios.

Esse propósito se mostra relevante em um país federativo de grande extensão territorial e diversidade sócio-econômica-cultural entre suas regiões e localidades que possui um sistema educacional não articulado nacionalmente, composto por, segundo o Censo da Escolar/Inep 2017, 184,1 mil escolas (78,2\% públicas), geridas por quase 6.000 entes federativos autônomos (5.570 redes municipais, 27 estaduais/distrital e a rede federal), além da iniciativa privada. Ao todo, essas escolas ofertavam 48,6 milhões de matrículas (81,7\% públicas) e contavam com 2,4 milhões de professores ( $77,2 \%$ da rede pública). No mesmo ano, o financiamento das escolas públicas (e conveniadas) de educação básica custou cerca de $\mathrm{R} \$ 232,2$ bilhões ao erário público. Esse montante representou 3,7\% do PIB e um gasto por aluno de $\mathrm{R} \$ 5.876$ ( $\mathrm{R} \$ 489,67$ por mês). Todavia, como será discutido mais adiante, a distribuição desse montante é bastante assimétrica e diversos indicadores evidenciam o subfinanciamento do setor.

A análise proposta no texto está baseada em três pressupostos. $\mathrm{O}$ primeiro é que os parâmetros de qualidade estabelecidos em lei devem ser definidos nacionalmente, para sinalizar o padrão abaixo do qual nenhuma escola pública poderia estar, para que as desigualdades de condições de oferta não comprometam o direito à educação, que, embora em contextos diferentes, deve garantir oportunidades e resultados equivalentes para todos os brasileiros.

O segundo pressuposto é que, mesmo em um sistema de educação de massa, o planejamento deveria sempre considerar as diversidades e diferenças dos sujeitos (alunos e profissionais), turmas, escolas e das redes públicas de ensino (municipais e estaduais). Neste artigo, compreende-se que a oferta educacional em cada município é uma construção histórica e, por isso, singular. Desse modo, a adoção de um padrão nacional poderá impactar de modo diferente cada município do ponto de vista orçamentário e, também, da infraestrutura escolar disponível (prédios) e do quadro de profissionais da educação (docentes e funcionários de escola). 
O terceiro é que, em um país federativo, deve haver mecanismos de identificação de diferenças na capacidade de financiar a oferta educacional dos entes federativos. A partir disso, a política de financiamento deve amenizar as desigualdades, para que o direito à educação nas localidades com menos recursos financeiros não seja precarizado a ponto de violar o princípio da igualdade estabelecido da Constituição Federal de 1988 (CF).

Como estratégia para auferir os recursos necessários para a operacionalização do princípio da "garantia de padrão de qualidade" estabelecido pela CF/1988 (BRASIL, 1988, art. 206, inc. VII) e os "padrões mínimos de qualidade de ensino, definidos como a variedade e quantidade mínimas, por aluno, de insumos indispensáveis ao desenvolvimento do processo de ensino-aprendizagem" estabelecidos pela Lei de Diretrizes e Bases (LDB - Lei no 9.394/1996, Art. 4º Inciso IX), a noção de CAQ começa a ser debatida no Brasil no final da década de 1980. O CAQ expressa a quantidade de recursos monetários por aluno necessária para dotar as escolas das condições de trabalho adequadas, como condição necessária, embora não suficiente, para um efetivo processo de ensino e aprendizagem (CARREIRA e PINTO, 2007). A proposta do CAQ altera a lógica do financiamento da educação básica vigente no Brasil, que é baseada na vinculação de parte das receitas de alguns impostos para a educação (lógica do "financiamento pré-estabelecido"). Essa estratégia tem sido fundamental nos períodos que vigorou, desde 1934, para garantir uma fonte estável de receitas para o setor (MELCHIOR, 1987), mas não garante um montante suficiente de recursos para a educação básica na maior parte das localidades brasileiras. A noção de CAQ propõe que a política de financiamento deve fazer face às necessidades e custos reais da oferta de ensino em condições de qualidade (lógica do "financiamento adequado"), como fazem os países desenvolvidos (LADD E LOEB, 2013).

Na década de 2000, surge a primeira estratégia metodológica concreta para calcular o valor do CAQ. Essa construção foi coordenada pela Campanha Nacional pelo Direito à Educação e publicada em Pinto (2006) e Carreira e Pinto (2007), com a denominação de Custo Aluno-Qualidade Inicial (CAQi) ${ }^{3}$. Graças a essa metodologia e mobilizações da sociedade, a noção de CAQi e CAQ foram incorporadas nas estratégias 20.6 e 20.7 da Meta 20 do PNE 2014-2024 (Lei 13.005/2014).

Neste artigo, o esforço orçamentário-financeiro que cada município deverá fazer para financiar a oferta de ensino com padrão de qualidade foi analisado por meio do Simulador de Custo Aluno-Qualidade (SimCAQ). O simulador é um sistema computa-

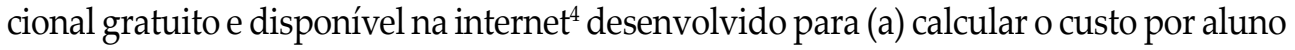
da oferta de ensino em condições de qualidade nas escolas públicas de educação básica (CAQ); e (b) oferecer suporte ao processo de elaboração, adequação e monitoramento dos planos educacionais (nacional, estaduais e municipais), visando a articulação das metas educacionais e a previsão do montante de recursos financeiros necessário para a oferta da educação básica em condições de qualidade no período dos planos. 
A concepção do simulador está em consonância com a noção de CAQ/CAQi apresentada por Carreira e Pinto (2007). Todavia, contando com recursos computacionais, propõe um novo método de cálculo que toma o sistema educacional real como elemento de análise ${ }^{5}$ e permite, além da apresentação de valor por aluno por etapa/modalidade, avaliar o impacto financeiro do padrão de qualidade no orçamento dos estados e municípios.

Para a consecução dos objetivos propostos, na parte empírica, foram selecionados três municípios do estado de Goiás de mesmo porte populacional (entre 5.001 e 10.000 habitantes) com características distintas quanto ao nível de receita própria em relação do total de receitas para a educação. São eles: Itarumã, Ouvidor e Santa Terezinha de Goiás. Destaca-se que cerca de $21 \%$ dos municípios brasileiros tem esse porte.

Todavia, do ponto de vista metodológico, é importante frisar que a seleção dos municípios não foi realizada no intuito de obter representatividade amostral e nem de realizar a inferência dos resultados para os demais municípios brasileiros. Este trabalho se caracteriza mais como um estudo de caso múltiplo, com a finalidade de demonstrar a importância de situar a realidade orçamentária-financeira de cada município brasileiro em relação ao financiamento da educação básica em condições de qualidade. Além disso, a escolha de municípios de um mesmo estado da federação considerou que a redistribuição de recursos entre estados e municípios no âmbito do Fundeb se dá em âmbito estadual, e isso, de algum modo, aproxima e caracteriza a realidade do financiamento dos municípios de cada UF.

Para atingir os objetivos, o artigo está estruturado em três seções. A primeira apresenta uma discussão sobre os parâmetros de qualidade, como requisito para o financiamento da educação em condições de qualidade no Brasil. A segunda seção apresenta os desafios para o financiamento da educação no Brasil na qual se apresenta o cálculo do CAQi nacional, aferido a partir do PQR, e a comparação entre os três casos do impacto da adoção do CAQi como parâmetro no financiamento da oferta educacional. Por fim, a última seção é reservada às considerações finais.

\section{Parâmetros de qualidade no financiamento ${ }^{6}$}

A Constituição Federal de 1988 (CF), ao estabelecer a qualidade do ensino como um princípio constitucional, indica que ao Estado brasileiro compete "a adoção de medidas, positivas e negativas, com o máximo de recursos disponíveis e progressivamente, com a finalidade de assegurar o exercício, por todos, da máxima qualidade na escolarização" (XIMENES, 2014, p. 234). A definição na CF da qualidade como princípio significa que ele deve orientar as demais normas constitucionais e legais da educação brasileira na sua garantia, principalmente para o alcance dos objetivos educacionais, expressos em síntese no Artigo 205 da Constituição Federal: "[...] pleno desenvolvimento da pessoa, seu preparo para o exercício da cidadania e sua qualificação para o trabalho" (BRASIL, 1988). 
No campo educacional, qualidade é um termo polissêmico (OLIVEIRA; ARAÚJO, 2005; CURY, 2014), que deve ser construído socialmente, levando em consideração o contexto histórico e cultural, alterando-se de acordo com o tempo e o espaço (DOURADO; OLIVEIRA; 2009).

Para Oliveira e Araújo (2005), do ponto de vista histórico, a qualidade da educação no Brasil foi construída e circulou na sociedade de modo simbólico com três significados distintos. O primeiro estava relacionado ao acesso, o segundo relacionado à ideia de fluxo, definido como número de alunos que progridem ou não dentro de determinado sistema de ensino. E a terceira ideia de qualidade, associada à aferição de desempenho mediante testes em larga escala. Esse aspecto se tornou mais evidente a partir da década de 1990, com aferições da qualidade por meio de testes de larga escala, e adentrou o século XXI com evidências de falta de condições de oferta e resultados educacionais desiguais e insatisfatórios. Apesar de não ter superado completamente os dois primeiros significados, principalmente entre os segmentos mais pobres da população, o principal desafio da educação brasileira atualmente é a oferta da educação de qualidade para todos, assegurando a aprendizagem de todos os estudantes, sendo para tanto imprescindível um financiamento adequado para assegurar condições igualitárias.

A universalização e ampliação do acesso é um importante avanço para a efetivação do direito à educação básica no Brasil, contudo, a expansão do acesso sem as devidas preocupações com a garantia de condições de qualidade e sem o correspondente financiamento adequado acabou por gerar, especialmente para os mais pobres, uma oferta educacional com condições de funcionamento das escolas em prédios com infraestrutura precária e muitas vezes sem o quadro de docentes e funcionários adequados e com a titulação necessária ${ }^{7}$. Desta forma, ainda em consonância com Oliveira e Araújo (2005), defende-se que uma educação de qualidade, no momento histórico atual, em face dos direitos e princípios constitucionais estabelecidos, deve ter um significado que englobe: a garantia de acesso; condições adequadas de permanência e aprendizagem; a promoção do desenvolvimento do ponto de vista humano, político e social; a emancipação e a inserção social; e a não (re)produção de mecanismos de diferenciação e de exclusão social.

Retomando a reflexão sobre um conceito de educação de qualidade, destaca-se que as referências estão associadas às diferentes ideias, pontos de vista e ou dimensões. As mais comuns são associadas a: qualidade como reputação das instituições educacionais; qualidade como recursos e insumos, com financiamento adequado, número adequado de professores e qualificação; qualidade como processo na natureza intrainstitucional das suas interações entre estudantes, professores e outros educadores; qualidade como conteúdo, relacionado ao corpo de conhecimento, habilidades e informações, com o currículo escolar; qualidade como resultados, associando qualidade ao conhecimento medido por meio de habilidades cognitivas, taxas de ingresso em níveis posteriores de ensino, renda, status educacional; e qualidade como valor agregado, como uma medida 
de mudança, referindo-se ao impacto, influência ou efeito das instituições nos estudantes (ADAMS, 1993).

Algumas dessas dimensões de qualidade implicam a alocação de recursos financeiros, tais como equipamentos, materiais didáticos, infraestrutura das escolas, salário dos profissionais da educação, número de alunos por turma e docente, alocação de funcionários, entre outros insumos. No entanto, outros aspectos não implicam diretamente a alocação de recursos, mas estão relacionados à gestão da escola e do sistema de ensino, ao currículo, ao projeto político-pedagógico, ao ambiente escolar, ao apoio e envolvimento da família no aprendizado dos alunos, entre outros (WALTENBERG, 2006).

No contexto brasileiro, visando dar concretude ao princípio constitucional da garantia do padrão de qualidade, a Lei de Diretrizes e Bases da Educação Nacional (LDB), Lei nº 9.394/1996, define, no Art. $4^{\circ}$, Inciso IX “padrões mínimos de qualidade de ensino" como a "variedade e quantidade mínimas, por aluno, de insumos indispensáveis ao desenvolvimento do processo de ensino-aprendizagem" (BRASIL, 1996). Ainda que seja uma definição muito vaga, a LDB considera relevante a associação entre insumos mínimos e padrões mínimos de qualidade. A LDB ainda determina o estabelecimento pela União, com a colaboração dos estados, do Distrito Federal e dos municípios, de um "padrão mínimo de oportunidades educacionais para o ensino fundamental baseado no cálculo do custo mínimo por aluno" (BRASIL, 1996, art. 74).

No que se refere à normatização de um padrão mínimo de qualidade definido nacionalmente, o Art. 38 da Lei n⿳o 11.494/2007, que regulamenta o Fundo de Manutenção e Desenvolvimento da Educação Básica e de Valorização dos Profissionais da Educação (Fundeb), aborda a responsabilidade dos entes federados ao afirmar sobre o financiamento da educação básica:

\begin{abstract}
A União, os Estados, o Distrito Federal e os Municípios deverão assegurar no financiamento da educação básica, previsto no Art. 212 da Constituição Federal, a melhoria da qualidade do ensino, de forma a garantir padrão mínimo de qualidade definido nacionalmente $\mathrm{O}$ parágrafo único. E assegurada a participação popular e da comunidade educacional no processo de definição do padrão nacional de qualidade [...] (BRASIL, 2007, art. 38).
\end{abstract}

O Parecer $n^{\circ}$ 08/2010 do CNE/CEB visava à regulamentação dos padrões mínimos de qualidade da educação básica nacional (Art. $4^{\circ}$, Inc. IX) e o estabelecimento do custo Aluno-Qualidade inicial (CAQi) como parâmetro da política de financiamento. Porém, esse parecer não foi homologado pelo Ministério da Educação e foi reexaminado pelo Parecer CNE/CEB n.03/2019, da relatora Maria Helena Guimarães de Castro, e aprovado unanimemente pela Câmara de Educação Básica (CEB) com alegação de que não compete ao CNE definir "definir o valor financeiro e a precificação do CAQi, exercida notadamente no Parecer CNE/CEB no 8/2010" (BRASIL, 2019: 25). 
Todavia, apesar da posição do CNE de que não compete a este órgão a definição do valor do CAQi, o conceito de CAQ e CAQi foi incorporado no Plano Nacional de Educação (PNE), Lei n⿳0 13.005, de 2014, cuja diretriz VIII, no Art.2º , prevê o "estabelecimento de meta de aplicação de recursos públicos, em educação, como proporção do Produto Interno Bruto - PIB, que assegure atendimento às necessidades de expansão, com padrão de qualidade e equidade" (BRASIL, 2014). A Meta 20 do PNE é "ampliar o investimento público em educação pública de forma a atingir, no mínimo, o patamar de 7\% (sete por cento) do Produto Interno Bruto (PIB) do País no 5ำ (quinto) ano de vigência desta Lei e, no mínimo, o equivalente a 10\% (dez por cento) do PIB ao final do decênio" (BRASIL, 2014).

Para isso, a estratégia 20.6 estabelece que, "no prazo de 2 (dois) anos da vigência deste PNE, será implantado o Custo Aluno-Qualidade Inicial (CAQi), referenciado no conjunto de padrões mínimos estabelecidos na legislação educacional e cujo financiamento será calculado com base nos respectivos insumos indispensáveis ao processo de ensino-aprendizagem e será progressivamente reajustado até a implementação plena do Custo Aluno-Qualidade (CAQ). No mesmo sentido, a estratégia 20.7 institui “implementar o Custo Aluno-Qualidade (CAQ) como parâmetro para o financiamento da educação de todas etapas e modalidades da educação básica, a partir do cálculo e do acompanhamento regular dos indicadores de gastos educacionais, com investimentos em qualificação e remuneração do pessoal docente e dos demais profissionais da educação pública, em aquisição, manutenção, construção e conservação de instalações e equipamentos necessários ao ensino e em aquisição de material didático-escolar, alimentação e transporte escolar (BRASIL, 2014).

Considerando que a educação de qualidade é uma concepção complexa que depende da atuação conjunta de diferentes fatores, atores e insumos, acreditamos que o financiamento adequado das escolas é um aspecto fundamental para garantir uma oferta de ensino em condições de qualidade, ou seja, recursos financeiros não garantem uma educação de qualidade (em todos seus aspectos e dimensões), mas são essenciais para o custeio de recursos e insumos que garantam condições de qualidade (ALVES, 2012; CARREIRA, PINTO, 2007).

Em um país federativo como o Brasil, com tantas desigualdades econômicas e sociais, se faz imprescindível o papel da União, no cumprimento de "função redistributiva e supletiva, de forma a garantir a equalização de oportunidades educacionais e um padrão mínimo de qualidade do ensino, mediante assistência técnica e financeira aos estados, ao Distrito Federal e aos municípios (BRASIL, 1988: art. 211), pois, o direito à educação pressupõe igualdade de condições para todos. Todavia, no modelo de federalismo adotado, há uma tensão na garantia desse direito, pois, maior descentralização corresponde maior desigualdade, sendo, portanto, fundamental o exercício de contrapeso da União no sentido de implementar ações supletivas (OLIVEIRA; SOUZA, 2010). 
Garantir padrões de qualidade na oferta educativa em nível nacional, ainda que respeitando as diversidades regionais e locais, por meio do estabelecimento do CAQi/CAQ como parâmetro para o financiamento educacional e complementação da União em sua função supletiva e redistributiva, é fundamental para reduzir a desigualdade nas condições da oferta e dos resultados educacionais.

Para operacionalizar os cálculos do CAQi e do CAQ conforme prevê a Meta 20 do Plano Nacional de Educação (Lei n 13.005/2014), e, por consequência, do orçamento necessário para financiá-lo, o SimCAQ utiliza um conjunto de parâmetros relativos aos insumos e recursos monetários denominados Padrão de Qualidade de Referência (PQR). Em alguma medida, os parâmetros que compõem o $\mathrm{PQR}$ dialogam com a necessidade de operacionalizar o que prevê o Art. 4⿳丷o da LDB/1996, sobre o dever do Estado para a garantia de "padrões mínimos de qualidade de ensino", padrões "definidos como a variedade e quantidade mínimas, por aluno, de insumos indispensáveis ao desenvolvimento do processo de ensino-aprendizagem [...]" (BRASIL, 1996).

Esses parâmetros expressam uma proposta de padrão de condições igualitárias de funcionamento das escolas públicas de educação básica ${ }^{8}$. Os parâmetros são relativos a: carga horária de ensino; tempo integral; tamanho das turmas; jornada dos professores; formação, remuneração e carreira de professores; composição do quadro, formação e remuneração de funcionários de escola; formação continuada; e insumos para funcionamento e manutenção das escolas (vide apêndice 1).

Cada elemento do PQR foi definido a partir de normatizações existentes, por exemplo, leis, decretos e resoluções em âmbito nacional e, na ausência destes, com base em documentos orientadores de políticas públicas, bem como em estudos e pesquisas acadêmicas. Além disso, alguns parâmetros foram definidos a partir do diagnóstico da realidade educacional, tendo em vista não propor um PQR inacessível ou inferior à situação já existente.

Os parâmetros apresentados no SimCAQ são apenas um esforço inicial de definição de condições mais igualitárias à oferta educacional e necessários para que o simulador possa elaborar cenários para o financiamento da educação básica em nível nacional ou nos estados e municípios. Desse modo, não se configuram como proposição definitiva, até porque compartilha-se do entendimento de que a oferta de ensino em condições de qualidade é uma construção histórica e social, que necessita de definição no âmbito de um processo democrático, por meio das instituições responsáveis para esta tarefa, em diálogo com a sociedade. 


\section{Desafios do financiamento nos municípios}

O SimCAQ, em seu modelo conceitual, é delineado para fazer um diagnóstico da realidade dos estados e municípios brasileiros a partir de diferentes fontes, comparar a realidade com um padrão de qualidade de referência (PQR) e simular os valores do CAQ e do orçamento necessário para a garantia da educação em condições de qualidade. Com ele, é possível simular rapidamente diferentes cenários de financiamento para municípios, estados e Brasil com a alteração de qualquer PQR.

A tabela 1 apresenta valores do CAQi para as 22 combinações de etapa/modalidade, área da localidade (urbana/runal) e turno (parcial/integral) 9 . O cálculo do CAQi é resultado da razão entre as despesas com a manutenção da rede de ensino, decorrentes dos paramentos do PQR utilizados pelo SimCAQ, e o número de matrículas de cada etapa/modalidade/área da localidade/turno ${ }^{10}$.

\section{Tabela 1 - Estimativas do CAQi por etapa, área da localidade e turno e comparação com VAA do Fundeb, valores para 2019}

\begin{tabular}{|c|c|c|c|c|c|c|}
\hline \multirow[t]{2}{*}{ Etapa } & \multirow[t]{2}{*}{$\begin{array}{c}\text { Área da } \\
\text { localidade }\end{array}$} & \multirow[t]{2}{*}{ Turno } & \multirow[t]{2}{*}{$\begin{array}{c}\text { CAQi } \\
2019 \text { (R\$) }\end{array}$} & \multicolumn{2}{|c|}{$\begin{array}{c}\text { Estimativas do } \\
\text { Valor-aluno-ano } \\
\text { (VAA) Fundeb 2018 } \\
\text { (R\$) }\end{array}$} & \multirow[t]{2}{*}{$\begin{array}{l}\text { CAQ } \\
\text { / VAA } \\
\text { menor }\end{array}$} \\
\hline & & & & Menor $^{2}$ & Maior $^{3}$ & \\
\hline \multirow{4}{*}{ Creche } & \multirow{2}{*}{ Urbana } & Parcial & 10.622 & 3.724 & 4.917 & 2,85 \\
\hline & & Integral & 19.132 & 4.210 & 5.558 & 4,54 \\
\hline & \multirow{2}{*}{ Rural } & Parcial & 17.174 & 3.724 & 4.917 & 4,61 \\
\hline & & Integral & 25.450 & 4.210 & 5.558 & 6,05 \\
\hline \multirow{4}{*}{ Pré-Escola } & \multirow{2}{*}{ Urbana } & Parcial & 6.324 & 3.400 & 4.489 & 1,86 \\
\hline & & Integral & 11.147 & 4.210 & 5.558 & 2,65 \\
\hline & \multirow{2}{*}{ Rural } & Parcial & 8.570 & 3.400 & 4.489 & 2,52 \\
\hline & & Integral & 17.352 & 4.210 & 5.558 & 4,12 \\
\hline \multirow{4}{*}{$\begin{array}{l}\text { Ensino } \\
\text { Fundamental - } \\
\text { anos iniciais }\end{array}$} & \multirow{2}{*}{ Urbana } & Parcial & 5.690 & 3.239 & 4.275 & 1,76 \\
\hline & & Integral & 7.666 & 4.210 & 5.558 & 1,82 \\
\hline & \multirow{2}{*}{ Rural } & Parcial & 7.833 & 3.724 & 4.917 & 2,10 \\
\hline & & Integral & 11.697 & 4.210 & 5.558 & 2,78 \\
\hline \multirow{4}{*}{$\begin{array}{l}\text { Ensino } \\
\text { Fundamental - } \\
\text { anos finais }\end{array}$} & \multirow{2}{*}{ Urbana } & Parcial & 5.292 & 3.562 & 4.703 & 1,49 \\
\hline & & Integral & 7.008 & 4.210 & 5.558 & 1,66 \\
\hline & \multirow{2}{*}{ Rural } & Parcial & 7.189 & 3.886 & 5.131 & 1,85 \\
\hline & & Integral & 10.867 & 4.210 & 5.558 & 2,58 \\
\hline
\end{tabular}




\begin{tabular}{|c|c|c|c|c|c|c|}
\hline \multirow[t]{2}{*}{ Etapa } & \multirow[t]{2}{*}{$\begin{array}{c}\text { Área da } \\
\text { localidade }\end{array}$} & \multirow[t]{2}{*}{ Turno } & \multirow[t]{2}{*}{$\begin{array}{c}\text { CAQi } \\
2019 \text { (R\$) }\end{array}$} & \multicolumn{2}{|c|}{$\begin{array}{c}\text { Estimativas do } \\
\text { Valor-aluno-ano } \\
\text { (VAA) Fundeb 2018 } \\
\text { (R\$) }\end{array}$} & \multirow[t]{2}{*}{$\begin{array}{l}\text { CAQ } \\
\text { / VAA } \\
\text { menor }\end{array}$} \\
\hline & & & & Menor $^{2}$ & Maior $^{3}$ & \\
\hline \multirow{4}{*}{ Ensino Médio } & \multirow{2}{*}{ Urbana } & Parcial & 5.329 & 4.048 & 5.344 & 1,32 \\
\hline & & Integral & 7.198 & 4.210 & 5.558 & 1,71 \\
\hline & \multirow{2}{*}{ Rural } & Parcial & 7.049 & 4.210 & 5.558 & 1,67 \\
\hline & & Integral & 11.720 & 4.210 & 5.558 & 2,78 \\
\hline \multirow[t]{2}{*}{ EJA } & Urbana & Parcial & 5.733 & 1.865 & 3.420 & 3,07 \\
\hline & Rural & Parcial & 7.717 & 1.865 & 3.420 & 4,14 \\
\hline CAQi médio & & & 7.011 & & & \\
\hline
\end{tabular}

Fonte: Elaborado pelos autores a partir dos resultados do SimCAQ (disponível em www.simcaq.c3sl.ufpr.br)

Notas:

(1) Valores da Portaria Interministerial MEC/MF nำ, de 28 de dezembro de 2018 e anexos disponíveis no site do FNDE (http://www.fnde.gov.br)

(2) Estados com MENOR valor-aluno: AL, AM, BA, CE, MA, PA, PB, PE e PI

(3) Estado com MAIOR valor-aluno = RS (não foram utilizados os valores de RR, devido às condições de financiamento que coloca essa UF com valores muito acima das demais)

A tabela mostra que os valores do CAQi são bastantes superiores aos valores por aluno estimados no Fundeb, queé a principal fonte de receitas para grande parte dos municípiose responsável por mais de $60 \%$ de todas as receitas para a educação básica do País (vide tabela 3). Também é possível notar pela comparação dos valores do CAQi das etapas em relação ao CAQi dos anos iniciais do ensino fundamental urbano parcial que os fatores de ponderação utilizados no Fundeb não correspondem à realidade dos custos das etapas.

Vale reforçar que os valores do CAQi são nacionais, uma vez que são gerados a partir de parâmetros de qualidade de referência para todo o País. Aqui não há afirmação de que esses parâmetros são ideais para todas as localidades, mas defende-se a importância de se ter parâmetros nacionais para as condições de oferta de ensino. Há uma discussão sobre a diferença do custo de vida e custo dos insumos serem diferentes nos estados e, por isso, há quem defenda um CAQi regional ou estadual. Há um grande risco nesse debate, porque, certamente, a diferenciação reforçaria as desigualdades, ao invés de reforçar o caráter equalizador que é um dos pilares da noção de CAQ. De tal modo, a proposta de CAQ nacional está em consonância com políticas como a do salário mínimo e o Piso Salarial Profissional Nacional (Lei no. 11.738/2018) e não impede políticas complementares ou supletivas para amenizar eventuais distorções.

Certamente, ofertar educação com padrão de qualidade que demande um valor por aluno superior ao que é redistribuído pelo Fundeb em cada estadoé, sem dúvida, desafiador para os municípios (que são os entes federativos que ficam com a menor parte da receita tributária). Mas a questão posta nesse artigo é: Qualé o tamanho do desafio para os municípios? 
Para analisar essa situação de modo concreto, foram selecionados três municípios de Goiás: Ouvidor, Itarumã e Santa Terezinha de Goiás. A tabela 2 apresenta as características gerais desses municípios. Como destacado na introdução, os casos selecionados possuem o mesmo porte populacional, mas distintas características educacionais e capacidades orçamentárias, considerando as receitas próprias e o valor-aluno-ano (VAA).

O município de Ouvidor tem características mais favoráveis quanto ao financiamento da educação, considerando a capacidade econômica medida pela arrecadação própria da ordem de 53,2\%; a oferta totalmente urbana (menor custo, portanto) e a taxa de municipalização da oferta de $51,2 \%$ (divide a responsabilidade pela educação básica com o poder público estadual quase na mesma proporção). O resultado dessa combinação de fatores é que o município teve o maior valor de receita por aluno-ano entre os 60 municípios de mesmo porte no estado de Goiás em 2017. É possível notar que a combinação dessas características em Santa Terezinha é adversa e, por isso, o município tem quase o menor VAA entre municípios de mesmo porte.

\section{Tabela 2 - Características dos municípios analisados}

\begin{tabular}{|c|c|c|c|c|c|}
\hline \multirow[b]{2}{*}{ Característica } & \multirow[b]{2}{*}{ Unidade } & \multirow[b]{2}{*}{ Ano } & \multicolumn{3}{|c|}{ Municípios } \\
\hline & & & Ouvidor & Itarumã & $\begin{array}{c}\text { Santa } \\
\text { Terezinha }\end{array}$ \\
\hline População & $\mathrm{N}$ & 2016 & 6.242 & 6.927 & 9.747 \\
\hline Pib per capita & $\mathrm{R} \$$ & 2016 & 95.795 & 32.935 & 13.240 \\
\hline IDH-M & & 2010 & 0,75 (alto) & 0,69 (médio) & 0,70 (alto) \\
\hline Matrículas rede pública & $\mathrm{N}$ & 2018 & 1.253 & 1.299 & 1.759 \\
\hline Escolas escolas públicas & $\mathrm{N}$ & 2018 & 3 & 6 & 12 \\
\hline Oferta urbana $^{1}$ & $\%$ & 2018 & $100,0 \%$ & $95,8 \%$ & $93,8 \%$ \\
\hline Municipalização² & $\%$ & 2018 & $51,2 \%$ & $53,7 \%$ & $67,7 \%$ \\
\hline Oferta Educação Infantil ${ }^{3}$ & $\%$ & 2018 & $24,3 \%$ & $20,5 \%$ & $20,8 \%$ \\
\hline Receita Própria ${ }^{4}$ & $\%$ & 2017 & $53,2 \%$ & $37,0 \%$ & $14,5 \%$ \\
\hline Valor-Aluno-Ano ${ }^{5}$ & $\mathrm{R} \$$ & 2017 & 8.637 & 6.810 & 4.872 \\
\hline \multicolumn{6}{|c|}{ 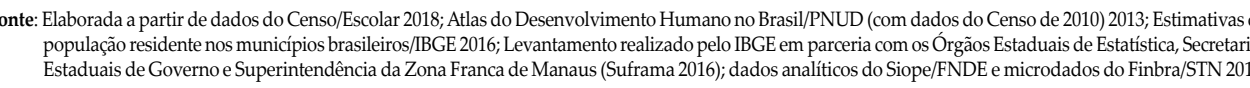 } \\
\hline \multicolumn{6}{|c|}{ 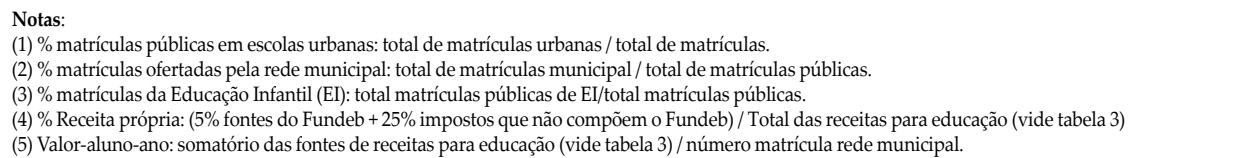 } \\
\hline
\end{tabular}


A tabela 3 apresenta a composição das receitas para o financiamento da educação básica para o Brasil e os municípios analisados. A tabela sintetiza e dá número aos valores auferidos pela atual política de financiamento da educação básica, que conta com as seguintes fontes de recursos: (a) vinculação de $25 \%$ da receita líquida de impostos de estados e municípios ${ }^{11}$, combinada com a redistribuição no âmbito de cada estado de $20 \%$ das fontes que compõem o Fundeb ${ }^{12}$; (b) receitas do Salário Educação ${ }^{13}$; (c) complementação da União (para os estados que não atingem o valor por aluno mínimo nacional) ${ }^{14}$.

Tabela 3 - Composição das receitas para o financiamento da educação básica por grupo de fontes, Brasil e municípios selecionados, 2017

\begin{tabular}{|c|c|c|c|c|c|c|c|c|c|}
\hline \multirow[t]{2}{*}{ Grupo } & \multirow[t]{2}{*}{$\begin{array}{l}\text { Fonte de } \\
\text { receitas }\end{array}$} & \multicolumn{2}{|l|}{ BRASIL } & \multicolumn{2}{|c|}{ Ouvidor-GO } & \multicolumn{2}{|c|}{ Itarumã-GO } & \multicolumn{2}{|c|}{$\begin{array}{c}\text { Santa } \\
\text { Terezinha de } \\
\text { Goiás-GO } \\
\end{array}$} \\
\hline & & $\mathrm{R} \$$ & $\%$ & $\mathbf{R} \$$ & $\%$ & $\mathbf{R} \$$ & $\%$ & $\mathbf{R} \$$ & $\%$ \\
\hline \multirow{3}{*}{ 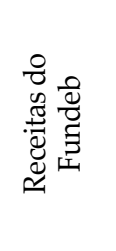 } & $\begin{array}{l}\text { Receitas oriundas } \\
\text { de Estados e } \\
\text { Municípios }\end{array}$ & 133.373.509.072 & 56,0 & 2.407 .551 & 42,0 & 2.502 .575 & 55,2 & 4.628 .820 & 76,6 \\
\hline & $\begin{array}{l}\text { Complementação } \\
\text { da União }\end{array}$ & 12.836 .050 .285 & 5,4 & & - & & - & & - \\
\hline & Total do Fundeb & 146.209.559.357 & 61,4 & 2.407 .551 & 42,0 & 2.502 .575 & 55,2 & 4.628 .820 & 76,6 \\
\hline \multirow{2}{*}{ 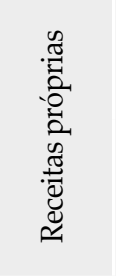 } & $\begin{array}{l}\% 5 \text { das fontes } \\
\text { que compõem o } \\
\text { Fundeb }\end{array}$ & 33.556 .547 .072 & 14,1 & 1.164 .900 & 20,3 & 1.009 .033 & 22,2 & 566.562 & 9,4 \\
\hline & $\begin{array}{l}\text { 25\% impostos } \\
\text { que não } \\
\text { compõem o } \\
\text { Fundeb }\end{array}$ & 40.859.134.810 & 17,1 & 1.883 .489 & 32,9 & 670.555 & 14,8 & 309.787 & 5,1 \\
\hline \multirow{2}{*}{ 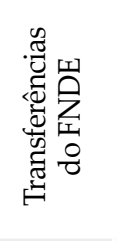 } & $\begin{array}{l}\text { Contribuição do } \\
\text { Salário-Educação }\end{array}$ & 12.445 .733 .726 & 5,2 & 195.122 & 3,4 & 198.691 & 4,4 & 362.046 & 6,0 \\
\hline & $\begin{array}{l}\text { Programas } \\
\text { federais de } \\
\text { distribuição } \\
\text { universal }\end{array}$ & 5.247.787.902 & 2,2 & 75.033 & 1,3 & 154.365 & 3,4 & 174.003 & 2,9 \\
\hline 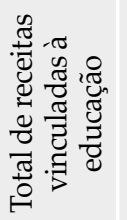 & & 238.318.762.867 & 100 & 5.726 .094 & 100 & 4.535 .218 & 100 & 6.041 .218 & 100 \\
\hline
\end{tabular}

Fonte: Financeiros: Dados analíticos do SIOPE/FNDE 2017 e Microdados do Finbra/Siconfi/STN 2017.

Educacionais: Microdados do Censo Escolar / INEP / 2016 e 2017. Disponíveis no Laboratório de Dados Educacionais (www.dadoseducacionais.c3sl.ufpr.br).

A tabela 3 mostra como a composição das receitas para financiamento da educação básica em cada localidade pode assumir características bastante peculiares. Diante da capacidade de arrecadação tributária própria e características da oferta de matrículas 
(número de matrículas em cada etapa/modalidade), a tabela mostra que os municípios podem ser mais ou menos dependentes dos recursos do Fundeb (o fundo representa $76,6 \%$ das receitas em Santa Terezinha, em Ouvidor, apenas 42\%). A tabela deixa claro que os municípios com maior proporção de receitas próprias têm maior receita por aluno-ano (tabela 2) e podem, desse modo, garantir um financiamento mais próximo dos valores do CAQi (tabela 1).

A tabela 4 apresenta as demandas para o ano de 2019 (projeção) por turmas, salas de aula (prédio, portanto), docentes, funcionários de escola e despesas correntes necessárias por ente federativo (estado e município) em relação ao que existe atualmente (2018) nas localidades, para atender o mesmo número de matrículas de 2018 (ou seja, sem prever nenhuma expansão ou redução da oferta) com padrão de qualidade. Para isso, o SimCAQ recalcula as demandas e projeta o quantitativo do sistema educacional "ideal" com base no PQR. Desse modo, o simulador fornece informações úteis para o planejamento orçamentário-financeiro, mas também para o planejamento físico da rede (número de prédios) e de pessoal (necessidade de contratação). 


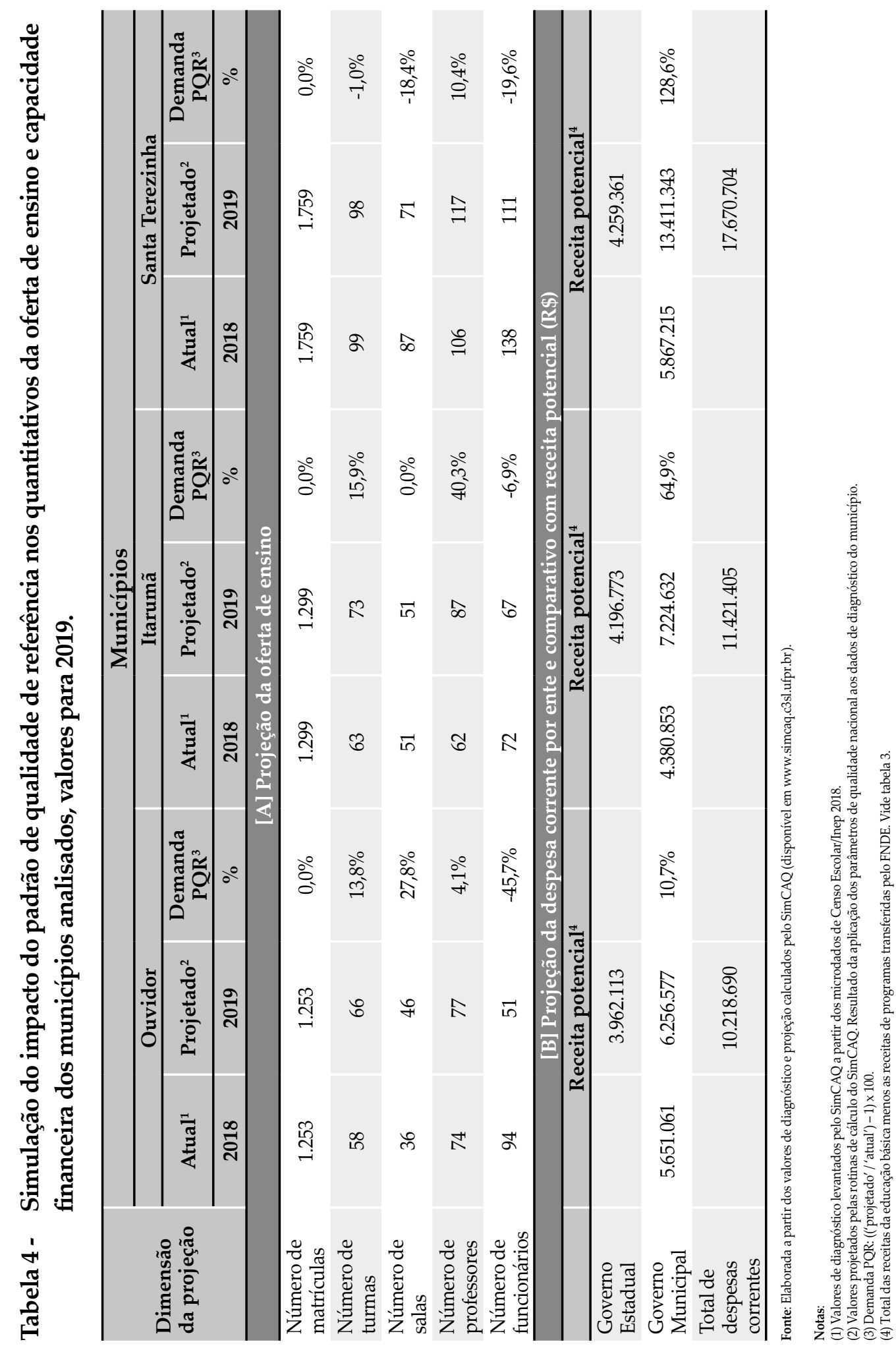


Os números da tabela 4 sugerem que os municípios analisados estão em situação bastante distinta e precisam de esforços diferentes, considerando a singularidade dos contextos historicamente construídos. Corroborando os dados da tabela 2, Ouvidor está em situação mais favorável. Ao todo, para financiar o CAQi 2019 para as matrículas da rede estadual e municipal, seria necessário um orçamento de $\mathrm{R} \$ 10,2$ milhões para despesas correntes em manutenção e desenvolvimento de ensino (MDE) ${ }^{15}$. Desagregando a despesa corrente por ente federativo (governo estadual e municipal), a partir do número de matrículas ofertado (vide taxa de municipalização na tabela 2), a tabela mostra que a rede municipal precisaria de $\mathrm{R}$ 6,26 milhões para financiar o CAQi. Considerando que esse município tem uma receita potencial de $\mathrm{R} \$ 5,65$ milhões, seria necessário um aumento de receita da ordem de 10,7\%. Vale notar que o valor da receita potencial retira o valor das transferências dos programas do FNDE apresentados na tabela 3 porque alimentação não é um item de MDE e, portanto, não está contido nos valores do CAQi (tabela 1) e o transporte não está na lista de PQR da versão atual do SimCAQ. Grande parte das receitas de programas do FNDE refere-se ao Programa Nacional de Alimentação Escolar (Pnae) e Programa Nacional de Apoio ao Transporte do Escolar (Pnate). Além da projeção do orçamento necessário, os números do SimCAQ sugerem que Ouvidor precisaria aumentar o número de turmas em 13,8\%. A indicação de aumento no número de salas de aula em $27,8 \%$ indica que os prédios das escolas públicas estaduais e municipais no município não tem número suficiente para atender o padrão de qualidade que faz adequação do número de alunos por turma em cada etapa e aumenta a proporção de matrículas em tempo integral. Igualmente, o quadro atual de professores não é suficiente. Seria necessária uma expansão de 4,1\% (contratação de três novos docentes). $\mathrm{O}$ número de funcionários, segundo os cálculos do simulador a partir do PQR, características das escolas dos municípios e os números apresentados no Censo Escolar/Inep 2018, poderia ser reduzido em $45,7 \%{ }^{16}$.

O município de Itarumã teria um desafio orçamentário mais expressivo, uma vez que necessitaria de um aumento nas receitas para educação da ordem de $64,9 \%$ (um aumento de $\mathrm{R}$ \$,38 milhões para $\mathrm{R}$ \$,22 milhões), para cobrir as despesas correntes necessárias ao financiamento da oferta de ensino em condições de qualidade na rede municipal. Do ponto de vista de adequação da oferta, seria necessário um aumento no número de turmas de $15,9 \%$ e a contratação 25 professores (aumento de 40,3\% do quadro). O número de salas de aula e funcionários parece ser suficiente para atender a demanda de adequação ao PQR.

O maior desafio, no entanto, é o do município de Santa Terezinha. Para fazer face ao orçamento necessário estimado em $\mathrm{R} \$ 13,4$ milhões, seria necessário aumentar as receitas da rede municipal (atualmente em $\mathrm{R} \$ 5,87$ milhões) em 128,6\%. O baixo VAA apresentado na tabela 2 anunciava o provável sub financiamento das condições de oferta existente no município. Além disso, os resultados sugerem a necessidade de contratar 11 professores 
(aumento do quadro em 10,4\%). Vale notar que o número de turmas, salas de aula e funcionários está acima do estimado como necessário.

Ainda cabe destacar que para os três casos analisados neste artigo não foram consideradas a ampliação de matrículas, necessária principalmente em creche e no atendimento dos cursos de educação de jovens e adultos.

\section{Considerações finais}

A democratização do direito à educação no Brasil, apesar de ter avançado significativamente nos últimos anos, ainda se apresenta como desafio para os diversos entes federados, especialmente no que se refere ao debate em torno da qualidade de oferta, da garantia de condições de igualdade de acesso e permanência e dos resultados medidos pelas avaliações em larga escala.

Tais debates apresentam diversas facetas, entre as quais a definição das condições de qualidade e dos insumos necessários à oferta educacional, além do papel dos diversos entes federados na garantia de tais condições.

Uma das grandes dificuldades em relação a essas questões refere-se ao levantamento de custo. Nesse sentido, o SimCAQ é apresentado como a ferramenta capaz de colaborar com a discussão, pois simula os valores necessários para garantir o CAQi, a partir de parâmetros de qualidade definidos nacionalmente. A partir de um conjunto de parâmetros, o SimCAQ apresenta os valores de CAQi que retratam a distância entre os VAA do Fundeb, praticados atualmente, e os valores necessários à garantia de um determinado conjunto de condições de qualidade. Mostra, também, a problemática definição dos fatores de ponderação no Fundeb atual.

O planejamento das redes públicas de ensino é uma tarefa fundamental e de grande complexidade. Desse modo, faz-se necessário o desenvolvimento e uso de mecanismos que consigam considerar múltiplos aspectos nessa tarefa. É nesse propósito que o SimCAQ pretende colaborar, ao fazer estimativas, considerando o grande volume de dados simultaneamente. Nos três casos analisados, foi possível mostrar o impacto do padrão de qualidade nacional em fatores determinantes (orçamento, infraestrutura escolar e quadro de profissionais da educação) para a garantia da oferta de ensino em cada município, considerando suas particularidades.

As análises desse artigo remetem à necessidade de ampliar as fontes de recursos, de modo a garantir o financiamento do CAQi. No atual momento histórico, diante das dificuldades fiscais dos entes subnacionais, acredita-se que o aumento da participação da União no financiamento da educação básica, por meio da complementação do Fundeb, seja uma das questões fundamentais para o novo Fundeb, que deve entrar em vigência a partir de 2020. Nos casos analisados, conforme mostrou a tabela 3, nenhum município 


\section{recebeu complementação da União, uma vez que no atual modelo do Fundo, Goiás não está entre os estados da federação que recebem complementação. Para além do aumento dos recursos da União no Fundo, é necessário revisar o modelo de redistribuição, para que municípios com VAA baixos, independentes do estado, possam receber complementação.}

\section{Recebido em: 21/09/2019 e Aprovado em: 28/09/2019}

\section{Notas}

1 Este artigo faz parte dos resultados do projeto Simulador de Custo Aluno-Qualidade (SimCAQ), financiado no período de 2016 a 2019 por um Termo de Execução Descentralizada (TED) firmado entre a Universidade Federal do Paraná (UFPR) e a Secretaria de Articulação com os Sistemas de Ensino do Ministério da Educação (Sase/MEC). Acesso ao simulador e outras informações em www.simcaq.c3sl.ufpr.br.

2 Para mais informações sobre a atuação da Campanha Nacional pelo Direito à Educação e sobre seu trabalho referente ao CAQ/CAQi consultar http://campanha.org.br/o-que-fazemos/custo-aluno-qualidade-inicial-e-aluno-qualidade/

3 O CAQi refere-se ao valor necessário a ser investido para a garantia de um conjunto de parâmetros de qualidade que visam a garantia de condições mais igualitárias entre as escolas brasileiras. O CAQ por sua vez representa a elevação desses padrões mínimos visando o cumprimento de várias metas do Plano Nacional de Educação, como, por exemplo, 25\% de matrículas em tempo integral, equiparação salarial dos professores com outros profissionais de mesmo nível de formação etc.

4 Disponível em www.simcaq.c3sl.ufpr.br.

5 O sistema educacional é caracterizado no banco de dados do simulador por informações de matrículas, escolas, turmas, professores, prédios escolares e de receitas e despesas coletados em bases de dados oficiais.

6 Parte das reflexões desta seção estão disponibilizadas na página eletrônica do SimCAQ, na parte "O que entendemos por uma educação de qualidade" (https://simcaq.c3sl.ufpr.br/quality).

7 Dados gerados a partir dos microdados do Censo Escolar/Inep 2017 apontam que nas escolas públicas $21,9 \%$ professores não têm formação em cursos de licenciatura; $31,1 \%$ dos professores das redes estaduais com vínculos de emprego temporário; $49,5 \%$ do total de matrículas em turmas com elevado número de alunos por turma; 56,5\% das escolas sem biblioteca; e 56,6\% sem laboratório de ciências. Segundo os microdados da PNAD contínua $2^{\mathrm{o}}$ trimestre/2017, os professores com formação em nível superior recebem remuneração equivalente a $73,1 \%$ da remuneração média dos demais profissionais de mesma formação.

8 Os valores e justificativas do PQR no SimCAQ podem ser consultados em https://simcaq.c3sl.ufpr.br/pqr

9 As modalidades educação especial e a educação profissional técnica (de nível médio) possuem grande número de especificidades nas condições de oferta e, por isso, requerem mais pesquisas para serem incorporadas em versão futura do simulador. Pretende-se avançar no cálculo do CAQ destas modalidades em nova fase da pesquisa. Atualmente, cada matrícula da educação especial e educação profissional é financiada com o mesmo valor de CAQ corresponde às etapas regulares em que os alunos estão matriculados.

10 O CAQ é calculado a partir da alocação dos custos às etapas de ensino, quando identificados diretamente a uma etapa/localidade/turno. As despesas comuns, como despesa com a conta de energia das escolas, são rateadas entre as etapas, tomando o percentual de matrículas de cada etapa em relação ao total como direcionador de custos. 
11 A CF estabelece no Art. 212 que "A União aplicará, anualmente, nunca menos de dezoito, e os Estados, o Distrito Federal e os Municípios vinte e cinco por cento, no mínimo, da receita resultante de impostos, compreendida a proveniente de transferências, na manutenção e desenvolvimento do ensino".

12 Vide a fonte das receitas do Fundeb no art. $3^{\text {o }}$ da Lei no. 11.494/2007.

13 A CF estabelece no Art. 212 §5ํque: “A educação básica pública terá como fonte adicional de financiamento a contribuição social do salário-educação, recolhida pelas empresas na forma da lei.

14 A Lei no. 11.494/2007 (Fundeb), estabelece no Art. 4: “A União complementará os recursos dos Fundos sempre que, no âmbito de cada Estado e no Distrito Federal, o valor médio ponderado por aluno (...) não alcançar o mínimo definido nacionalmente (...)".

15 Vide a lista de despesas consideradas MDE no Art. 70 da LDB/1996.

16 Vide o debate sobre as dificuldades para estimar o número de funcionários de escola a partir dos dados do Censo Escolar/Inep em Alves et al. (2019).

\section{Referências}

ADAMS, Don. Defining Educational Quality. Arlington, VA, Institute for International Research, 1993.

ALVES. Thiago. Desenvolvimento de um modelo de previsão de custos para planejamento de sistemas públicos de educação básica em condições de qualidade: uma aplicação a municípios de Goiás. 353f. Tese (Doutorado em Administração) - Faculdade de Economia, Administração e Contabilidade, Universidade de São Paulo, São Paulo, 2012.

ALVES, Thiago et al. Dimensionamento do quadro de funcionários das escolas de educação básica no Brasil. Revista Brasileira de Política e Administração da Educação. Porto Alegre:UFRGS, v. 35, n. 1, p. $207-228,2019$.

BRASIL. Lei n 9.394, de 20 de dezembro de 1996. Estabelece diretrizes e bases da educação nacional. Diário Oficial da União, Brasília, DF, 23 dez. 1996. Disponível em: http://www.planalto.gov.br/ ccivil_03/leis/19394.htm. Acesso em: 15 fev. 2019.

BRASIL. Lei federal no 11.494. Regulamenta o Fundo de Manutenção e Desenvolvimento da Educação Básica e de Valorização dos Profissionais da Educação (Fundeb). Brasília, 20 jun. 2007. Disponível em: http://www.planalto.gov.br/ccivil_03/_ato2007-2010/2007/lei/111494.htm. Acesso em: 15 fev. 2019.

BRASIL. Lei nº 13.005/2014. Plano Nacional de Educação Aprova o Plano Nacional de Educação - PNE e dá outras providências. Diário Oficial da União, Brasília, DF, 26 jun. 2014. Disponível em: http://www. planalto.gov.br/ccivil_03/_ato2011-2014/2014/lei/113005.htm. Acesso em: 15 fev. 2019.

BRASIL. Parecer CNE/CEB № 8/2010. Estabelece normas para aplicação do inciso IX do artigo 4o da Lei no 9.394/1996 (LDB), que trata dos padrões mínimos de qualidade de ensino para a Educação Básica pública. 2010. Disponível em: http://portal.mec.gov.br/index.php?option=com_ docman\&view=download\&alias=5368-pceb008-10\&category_slug=maio-2010pdf\&Itemid=30192. Acesso em: 15 fev. 2019.

BRASIL. Parecer CNE/CEB № 3/2019. Reexame do Parecer CNE/CEB no 8/2010, que estabelece normas para a aplicação do inciso IX do artigo 4o da Lei no 9.394/96 (LDB), que trata dos padrões mínimos de qualidade de ensino para a Educação Básica pública. http://portal.mec.gov.br/index. 
php?option=com_docman\&view=download\&alias=110291-pceb003-19-1\&category_slug=abril2019-pdf\&Itemid=30192. Acesso: 23 ago. 2019.

CARREIRA, Denise; PINTO, José Marcelino Rezende. Custo Aluno-Qualidade Inicial: rumo à educação pública de qualidade no Brasil. São Paulo: Global, Campanha Nacional pelo Direito à Educação, 2007.

CURY, Carlos Roberto Jamil. A qualidade da educação brasileira como direito. Educação e Sociedade, Campinas, v. 35, n. 129, p.1053-1066, out. 2014.

INEP. Problematização da qualidade em pesquisa de custo-aluno-ano em escolas de educação básica: relatório de pesquisa. Instituto Nacional de Estudose Pesquisas Educacionais Anísio Teixeira. Brasília. 2006

DOURADO, Luiz Fernandes; OLIVEIRA, João Ferreira de. A qualidade da educação: perspectivas e desafios. Cadernos Cedes, Campinas, v. 29, n. 78, ago. 2009.

LADD, Helen; LOEB, Susanna. The Challenges of Measuring School Quality: Implications for Educational Equity. In. ALLEN, D; REICH, R. (Orgs.). Education, Justice, and Democracy, Chicago, University of Chicago Press, 2013. (pp. 22-55).

MELCHIOR, José Carlos Araújo. O financiamento da educação no Brasil. São Paulo, EPU, 1987. 156p.

OLIVEIRA, Romualdo Portela de; ARAUJO, Gilda Cardoso de. Qualidade do ensino: uma nova dimensão da luta pelo direito à educação. Rev. Bras. Educ., Rio de Janeiro, n. 28, abr. 2005. Disponível em: http://www.scielo.br/pdf/rbedu/n28/a02n28.pdf

OLIVEIRA, Romualdo Portela de. P.; SOUSA, Sandra Zákia. Introdução. In: OLIVEIRA, Romualdo Portela; SANTANA, Wagner. (Org.). Educação e Federalismo no Brasil: combater as desigualdades e garantir a diversidade. 1ed.Brasília: UNESCO, 2010, v. 1, p. 9-35.

PINTO, José Marcelino de Rezende. Uma proposta de custo-aluno-qualidade na educação básica. Revista Brasileira de Política e Administração da Educação, Porto Alegre: UFRGS, v. 22, p. 197-227, 2006.

WALTENBERG, Fábio. D. Teorias econômicas de oferta de educação: evolução histórica, estado atual e perspectivas. Educação e Pesquisa, São Paulo: USP, v. 32, n. 1, p. 117-136, 2006.

XIMENES, Salomão Direito à qualidade na educação básica: teoria e crítica. São Paulo:QuartierLatin, 2014b. 


\section{Apêndice I - Padrão de Qualidade de Referência (PQR)}

Os parâmetros apresentados, a seguir, foram definidos pela equipe da pesquisa SimCAQ em parceria com a Campanha Nacional pelo Direito à Educação. Eles subsidiaram o cálculo do CAQi, ano-base 2019.

\section{A) Carga horária de ensino}

\begin{tabular}{l|c|c|c|c|c|c}
\hline Aspectos & Creche & PRE & EF-AI & EF-AF & EM & EJA \\
\hline $\begin{array}{l}\text { Dias letivos por semana } \\
\text { Número de dias }\end{array}$ & 5 & 5 & 5 & 5 & 5 & 5 \\
\hline $\begin{array}{l}\text { Jornada diária de ensino } \\
\text { Diurno parcial }\end{array}$ & 4 & 4 & 4 & 4 & 4 & 4 \\
Tempo Integral & 10 & 10 & 7 & 7 & 7 & - \\
\hline Noturno & - & - & - & - & 4 & 4 \\
\hline Tempo integral & & & & & & \\
\hline Percentual de matrículas em turno integral & $80 \%$ & $25 \%$ & $12,5 \%$ & $12,5 \%$ & $12,5 \%$ & - \\
\hline
\end{tabular}

\section{B) Tamanho das turmas}

\begin{tabular}{|c|c|c|c|c|c|c|c|c|c|c|}
\hline \multirow[t]{2}{*}{ Localização } & \multirow[t]{2}{*}{ Aspecto } & \multicolumn{4}{|c|}{ Creche } & \multirow{2}{*}{ 坓 } & \multirow{2}{*}{ 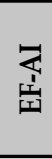 } & \multirow{2}{*}{ 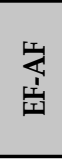 } & \multirow{2}{*}{$\sum_{i=1}$} & \multirow{2}{*}{ 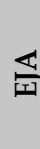 } \\
\hline & & $\begin{array}{l}<1 \\
\text { ano }\end{array}$ & $\begin{array}{c}1 \\
\text { ano }\end{array}$ & $\begin{array}{c}2 \\
\text { anos }\end{array}$ & $\begin{array}{c}3 \\
\text { anos }\end{array}$ & & & & & \\
\hline \multirow[t]{2}{*}{$\begin{array}{l}\text { Escolas } \\
\text { urbanas }\end{array}$} & $\begin{array}{l}\text { Alunos por turma } \\
\text { (máximo) }\end{array}$ & 6 & 7 & 8 & 15 & 20 & 25 & 30 & 30 & 25 \\
\hline & $\begin{array}{l}\text { Docentes por turma } \\
\text { (mínimo) }\end{array}$ & 1 & 1 & 1 & 1 & 1 & 1 & 1 & 1 & 1 \\
\hline \multirow[t]{2}{*}{$\begin{array}{l}\text { Escolas do } \\
\text { campo }\end{array}$} & $\begin{array}{l}\text { Alunos por turma } \\
\text { (máximo) }\end{array}$ & 6 & 7 & 8 & 10 & 15 & 17 & 20 & 22 & 18 \\
\hline & $\begin{array}{l}\text { Docentes por turma } \\
\text { (mínimo) }\end{array}$ & 1 & 1 & 1 & 1 & 1 & 1 & 1 & 1 & 1 \\
\hline
\end{tabular}

\section{C) Jornada de trabalho docente}

\begin{tabular}{lc}
\hline Jornada semanal de trabalho (em horas): & 40 \\
\hline Jornada SEM interação com alunos: & $33,4 \%$ \\
\hline Jornada COM interação com alunos: & $66,6 \%$ \\
\hline
\end{tabular}




\section{D) Carreira e remuneração dos professores}

\begin{tabular}{|c|c|c}
\hline Nível / Classe & Nível de formação & Remuneração bruta mensal (R\$) \\
\hline P1 & Médio & $2.557,74$ \\
P2 & Superior & $4.477,50$ \\
P3 & Especialização & $4.925,25$ \\
P4 & Mestrado & $5.820,75$ \\
P5 & Doutorado & $6.716,25$ \\
\hline
\end{tabular}

\section{E) Quadro de funcionários e remuneração}

\begin{tabular}{|c|c|c|c|c|c|c|c|}
\hline \multirow[b]{2}{*}{ Função } & \multirow[b]{2}{*}{$\begin{array}{l}\text { Nível de } \\
\text { Formação }\end{array}$} & \multicolumn{2}{|c|}{ Localização } & \multicolumn{3}{|c|}{ Critérios de alocação por escola } & \multirow[b]{2}{*}{$\begin{array}{l}\text { Remuneração } \\
\text { bruta mensal } \\
\text { (R\$) }\end{array}$} \\
\hline & & urbano & rural & $\begin{array}{c}\text { Profissional } \\
\text { por } \\
\text { matrícula }\end{array}$ & $\begin{array}{l}\text { Mínimo } \\
\text { por } \\
\text { escola }\end{array}$ & $\begin{array}{c}\text { Máximo } \\
\text { por } \\
\text { escola }\end{array}$ & \\
\hline Direção & Superior & $\operatorname{sim}$ & $\operatorname{sim}$ & & 1 & 1 & $5.371,25$ \\
\hline Vice-direção & Superior & $\operatorname{sim}$ & & 600 & & 3 & $5.147,45$ \\
\hline $\begin{array}{l}\text { Coordenação } \\
\text { pedagógica }\end{array}$ & Superior & $\operatorname{sim}$ & & 350 & 1 & & $5.147,45$ \\
\hline Biblioteconomia* & Superior & sim & $\operatorname{sim}$ & & 1 & 1 & $4.477,50$ \\
\hline $\begin{array}{l}\text { Biblioteconomia } \\
\text { (técnico) }\end{array}$ & Médio & $\operatorname{sim}$ & & & 1 & 1 & $2.557,74$ \\
\hline $\begin{array}{l}\text { Secretaria } \\
\text { Escolar }\end{array}$ & Médio & $\operatorname{sim}$ & & 350 & 1 & & $2.557,74$ \\
\hline $\begin{array}{l}\text { Multimeios } \\
\text { didáticos }\end{array}$ & Médio & sim & & 250 & 1 & & $2.557,74$ \\
\hline Infraestrutura & Médio & $\operatorname{sim}$ & & 150 & 1 & & $2.557,74$ \\
\hline Alimentação & Médio & $\operatorname{sim}$ & $\operatorname{sim}$ & 125 & 1 & & $2.557,74$ \\
\hline
\end{tabular}

Nota: ${ }^{*}$ ) função não alocada para estabelecimentos que ofertam exclusivamente creche

\section{F) Formação continuada}

\begin{tabular}{lcc}
\hline Tipo de formação & Unidade de medida & Valor unitário (R\$) \\
\hline Formação continuada de professores & profissional/ano & 600,00 \\
\hline Formação continuada de funcionários de escolas & profissional/ano & 600,00 \\
\hline
\end{tabular}




\section{G) Funcionamento e manutenção das escolas}

\begin{tabular}{|l|c|c}
\hline Item & Unidade de medida & Preço unitário (R\$) \\
\hline Tarifa de água & Aluno/Mês & 4,00 \\
\hline Tarifa de energia & Aluno/Mês & 4,00 \\
\hline Tarifa de telefone / Internet & Aluno/Mês & 4,00 \\
\hline Material de limpeza & Aluno/Mês & 2,33 \\
\hline Material de escritório & Aluno/Mês & 1,00 \\
\hline Conservação predial & Aluno/Ano & 200,00 \\
\hline Manutenção e reposição de equipamentos & Aluno/Ano & 230,00 \\
\hline Kit de materiais didáticos & Aluno/Ano & 243,10 \\
\hline Projetos de ação Pedagógica & Aluno/Ano & 180,00 \\
\hline
\end{tabular}

\section{H) Encargos e adicionais}

\begin{tabular}{l|c}
\hline Aspectos & $\%$ \\
\hline Encargos sociais & $20,0 \%$ \\
\hline Estimativa da despesa com a área administrativa central da rede em relação aos custos das escolas & $7,5 \%$ \\
\hline Adicional para professores da Educação do campo & $15,0 \%$ \\
\hline
\end{tabular}

